\title{
CULTURA PEDAGÓGICA E FORMAÇÃO DE PROFESSORES: A BIBLIOTECA DA ESCOLA NORMAL DE PIRACICABA $(1911-1920)^{1}$
}

\author{
Ana Clara Bortoleto Nery \\ Universidade Estadual Paulista, Brasil.
}

\begin{abstract}
Resumo
Pensando a biblioteca da escola de formação de professores como espaço de organização de cultura pedagógica, este artigo tem como objeto a biblioteca da Escola Normal de Piracicaba, interior de São Paulo, entre os anos de 1911 e 1920. Constituída ao longo do ciclo de vida da Escola Complementar de Piracicaba (1896-1911), e oficializada a partir de 1911, a biblioteca, além de espaço de formação do professor da Escola Normal e do aluno-leitor, teve o papel de organizar e disseminar uma determinada cultura pedagógica ao selecionar, ordenar e disponibilizar um conjunto de saberes, próprios da profissão docente. Sobre o estudo da cultura pedagógica incide a análise desta biblioteca.

Palavras-chave: cultura pedagógica, biblioteca escolar, escola normal.
\end{abstract}

\section{EDUCATIONAL CULTURE AND TEACHERS TRAINING: THE LIBRARY OF NORMAL SCHOOL OF PIRACICABA (1911-1920)}

\begin{abstract}
Thinking the library at training school for teachers as a space that organizes the educational culture, this paper has as its object the library of Normal School of Piracicaba, interior of São Paulo, between the years 1911 and 1920. Constituted along the life cycle of Complementary School of Piracicaba (1896-1911) and officialized starting from 1911, the library, besides being a place for teaching education at Normal School and for the student-reader, plays the role of organizing and disseminating a particular educational culture when select, order and deliver a group of knowledge proper to the teaching profession. About the study of educational culture focuses the analysis of this library.

Key-words: educational culture, school library, normal school.
\end{abstract}

\footnotetext{
${ }^{1}$ Esse texto foi, originalmente, apresentado no $6^{\circ}$ Congresso Brasileiro de História da Educação, realizado Vitória/ES, em 2011. É produto de pesquisa desenvolvida com auxílio da Fapesp.
} 


\section{CULTURA PEDAGÓGICA Y FORMACIÓN DE PROFESORES: \\ LA BIBLIOTECA DE LA ESCUELA NORMAL DE PIRACICABA (1911-1920)}

Resumen

Pensando en la biblioteca de la escuela de formación de profesores como espacio de organización de cultura pedagógica, este artículo tiene como objeto la biblioteca de la Escuela Normal de Piracicaba, interior de São Paulo, entre los años de 1911 y 1920. Constituida a lo largo del ciclo de vida de la Escuela Complementar de Piracicaba (1896-1911) y oficializada a partir de 1911, la biblioteca, además de espacio de formación del profesor de la Escuela Normal y del alumno-lector, tendrá el papel de organizar y diseminar una determinada cultura pedagógica al seleccionar, ordenar y disponer un conjunto de saberes, propios de la profesión docente. Sobre el estudio de la cultura pedagógica incide el análisis de esta biblioteca.

Palabras-clave: cultura pedagógica, biblioteca escolar, escuela normal.

\section{CULTURE PÉDAGOGIQUE ET FORMATION D'ENSEIGNANTS: LA BIBLIOTHĖQUE DE L'ÉCOLE NORMALE DE PIRACICABA (1911-1920)}

\section{Résume}

Cet article a pour objet la Bibliothèque de l'École Normale de Piracicaba, à l'intérieur de São Paulo, entre les années 1911 et 1920, parce qu'elle représente un lieu de formation d'enseignants et organisation de culture pédagogique. Cette Bibliothèque qui a été constituée au long du cycle de vie de l'École Complémentaire de Piracicaba (1896-1911) et officialisée à partir de 1911 aura le rôle d'organiser et disséminer une certaine culture pédagogique en raison de sélectionner, trier et distribuer un ensemble de connaissances propres à la profession enseignante. Elle symbolise un espace de formation de l'enseignant de l'École Normale et de l'élève-lecteur. L'étude de la culture pédagogique se concentre sur l'analyse de cette bibliothèque.

Mots-clé: culture pédagogique, bibliothèque scolaire, école normale. 
lém de pensar a escola normal como espaço de produção e circulação de
saberes, conforme apontado anteriormente por mim (Nery, 2007) e por Marta
Carvalho (Carvalho, 2001), ela também pode ser compreendida como lugar de constituição de uma cultura pedagógica, arquitetada num espaço cultural singular: a biblioteca escolar.

As bibliotecas das escolas normais foram as depositárias do conjunto de saberes pedagógicos e educacionais considerado essencial para a formação do professor primário. Ao estudar esse conjunto de saberes, caracterizamos a cultura pedagógica da Escola Normal de Piracicaba, que se dedicou à formação do professor primário entre os séculos 19 e 20.

O presente artigo tem como preocupação central analisar aspectos da cultura pedagógica constituída pelo acervo da biblioteca da Escola Normal de Piracicaba ${ }^{2}$, entre os anos de 1911 e 1920. O estudo do acervo dessa biblioteca, constituído ao longo da segunda década do século 20, tendo como espólio inicial o acervo da Escola Complementar de Piracicaba, foi realizado a partir dos dados materiais dos livros voltados à formação de professores.

A biblioteca escolar das escolas de formação de professores é aqui considerada como um conjunto de materiais, em especial de livros que, destinados ao uso do professor e à leitura escolar, "organizam e constituem a cultura pedagógica representada como necessária ao desempenho escolar de seu destinatário, o professor" (Carvalho, 2007, p. 18) e o aluno-mestre. Assim, a biblioteca escolar das escolas normais foi considerada espaço de atividades de formação do professor e do futuro professor. $\mathrm{O}$ estudo da organização de tais bibliotecas, voltadas para a formação do professor, traz a tona elementos constitutivos da formação cultural e pedagógica e do estabelecimento de práticas específicas, que permitem uma melhor compreensão do período em foco.

A incipiente bibliografia sobre a Escola Normal de Piracicaba e a necessidade de compreender o processo pelo qual o acervo da biblioteca se constitui e chega até nós são as justificativas para as reflexões que desenvolvidas neste artigo.

\section{A biblioteca da Escola Normal de Piracicaba}

A biblioteca da Escola Normal de Piracicaba ${ }^{3}$ foi constituída a partir da reunião de várias bibliotecas criadas na escola. Pelo Livro de Tombo ${ }^{4}$ e pela documentação analisada é possível localizar, pelo menos, três bibliotecas. A primeira delas é a própria biblioteca da Escola Normal de Piracicaba, voltada à formação de professores. A segunda é a biblioteca infantil, destinada às crianças da Escola Modelo Anexa, que tinham aulas de leitura na biblioteca da Escola Normal. Outra biblioteca é a de Geografia, constituída

\footnotetext{
2 A Escola Normal de Piracicaba foi produto da transformação da Escola Complementar de Piracicaba (1896-1911) em Escola Normal Primária de Piracicaba. Tal instituição tem a denominação atual de Escola Estadual Sud Mennucci, em Piracicaba/SP.

${ }^{3} \mathrm{O}$ acervo da antiga Biblioteca da Escola Normal de Piracicaba encontra-se na Escola Estadual Sud Mennucci, em Piracicaba. Este acervo foi separado do acervo da atual biblioteca, no final dos anos de 1990 , apesar de alguns volumes da antiga biblioteca ter se incorporado ao novo, principalmente os livros de literatura.

${ }^{4}$ Escrituração feita a partir de 1950 e que apresenta dados do acervo antigo e as novas aquisições.
} 
nos anos de 1940, que pertencia ao Ginásio anexo à Escola Normal. Todas elas passam a ser uma só a partir do decreto n. 19.525-A, de 27 de junho de 1950.

O trabalho foi desenvolvido a partir de dois indícios principais: os carimbos dos livros e o Anuário do Ensino (1909). Os carimbos são os principiais indícios do momento em que o livro entrava para o acervo da biblioteca. Nessa biblioteca os carimbos acompanham a denominação da instituição em cada momento histórico. O espólio que dá origem ao acervo é representado pelo carimbo Escola Complementar. O período em foco é representado pelo carimbo com os dizeres Escola Normal Primária de Piracicaba. Por este meio localizamos e classificamos os livros do período eleito.

Outro indício de existência da biblioteca da Escola Complementar de Piracicaba é extraído do relatório apresentado por João Lourenço Rodrigues ao secretário do Interior, em 1909, publicado no Anuário do Ensino de 1909. Ao iniciar sua conferência, na Escola Complementar de Piracicaba, Rodrigues diz que "ante-hontem, depois de haver visitado a exposição dos trabalhos deste estabelecimento, eu fui ter á sua bibliotheca e alli encontrei, entre outros, um livro que pertencera ao saudoso dr. Prudente de Moraes e trazia a sua assignatura" (Annuario do Ensino, 1909, p. 202).

A observação de João Lourenço Rodrigues de que o livro foi doado por Prudente de Moraes, tendo pertencido ao seu acervo pessoal, revela o principal dispositivo de constituição do acervo da biblioteca da Escola Complementar. Os livros eram, em sua maioria, fruto de doações. Havia também livros adquiridos pela escola, como Lições de pedologia e pedagogia experimental, do professor da Universidade Nova de Bruxellas, Faria de Vasconcelos, e Curso de zootechnia geral e especial, de Adolpho Cavalcanti. Os livros comprados pela escola tinham o carimbo da Escola Complementar. Os obtidos por doação não recebiam o carimbo, apenas continham a dedicatória, com data. Não foi possível estabelecer quando a biblioteca começou a ser organizada, nem quando Fernando Paes de Almeida, formado pela Escola Complementar em 1904, assumiu a função de amanuense-bibliotecário.

No momento em que esta biblioteca se constitui havia outras instituições na cidade que também possuíam suas bibliotecas. O município já contava com o Gabinete de Leitura, um embrião de biblioteca pública municipal cujo acervo, segundo Elias Neto (2000), era mantido por meio de pagamento de jóia e mensalidades pelo público leitor. O Colégio Piracicabano e o Colégio d'Assunção de Nossa Senhora também tinham suas bibliotecas.

No entanto, uma instituição criada na cidade por pessoas ligadas à Escola Complementar parece ter sido um importante veículo de divulgação cultural através de suas atividades e de sua biblioteca: a Universidade Popular ${ }^{5}$. Nesta instituição reuniamse, dentre outros, Sud Mennucci, Thales Castanho de Andrade, Fabiano Lozano, Honorato Faustino e Erotides de Campos, todos ligados à Escola Complementar de Piracicaba, e Leo Vaz, que então era aluno da Escola Complementar. A Universidade Popular chegou a constituir uma biblioteca aberta ao público e este acervo continuou a

\footnotetext{
${ }^{5}$ A Universidade Popular, iniciativa de um grupo de intelectuais piracicabanos, foi criada em 25 de agosto de 1910. No artigo $1^{\circ}$ do estatuto estava previsto que sua finalidade seria o ensino, uma vez que "a vulgarização das matérias que são objeto do ensino secundário e superior, no que diz respeito às ciências, à literatura, às artes em geral e a todos os ramos da atividade humana - sociologia, religião, filosofia, comércio, indústria, agricultura, etc." (Elias Netto, 2000, p. 130).
} 
existir após a sua extinção. Posteriormente, parte deste acervo foi incorporada à biblioteca da Escola Normal de Piracicaba. É bem provável que alguns de seus livros tenham chegado ao acervo da biblioteca da Escola Normal pelas mãos de um de seus membros ligado à Universidade Popular.

A data de instalação da biblioteca da Escola Normal de Primária Piracicaba é 29 de março de 1911, mesma data em que a Escola Complementar é transformada em Escola Normal Primária de Piracicaba. É a partir deste ano que as bibliotecas das escolas normais começam a contar com recursos definidos no orçamento do Estado. No orçamento da Secretaria do Interior, referente à Diretoria Geral da Instrução Pública, nos anos de 1911-1913, havia a rubrica Livros para bibliotheca, ou seja, havia orçamento específico para este setor da escola. O orçamento do Estado para o exercício financeiro de 1912, por exemplo, aponta a destinação de verbas específicas para a aquisição de livros para a biblioteca da Escola Normal Primária de Piracicaba.

Neste mesmo orçamento é possível verificar que a quantia destinada, por esta mesma rubrica, para as escolas normais secundárias era praticamente o dobro da destinada às escolas normais primárias. Dentre a rubrica para as escolas normais primárias havia variação de uma escola para outra. Assim, por exemplo, o montante destinado à aquisição de livros para a biblioteca, no ano de 1913, para a Escola Normal Secundária de São Carlos, foi cinco contos de réis; para a Escola Normal Primária de Botucatu, três contos de réis; e para a Escola Normal Primária de Piracicaba, dois contos de réis.

\section{Análise material dos livros: a constituição da cultura pedagógica na biblioteca da Escola Normal Primária de Piracicaba}

Antes de chegar ao acervo de uma biblioteca, cada um dos livros passa por uma série de etapas que contribuem para a composição de sua materialidade (Chartier, 1994). Partindo da composição do texto pelo autor, que é encaminhado a um editor, passa por uma tipografia até a sua composição em formato de livro. Neste percurso, o texto do autor já sofreu as interferências do editor, por meio de um conjunto de dispositivos, incluindo os tipográficos, que interferem nas prescrições e nos usos deste livro. Após esta transformação do texto em livro, outras interferências serão sofridas pelo texto. No caso das bibliotecas escolares das escolas normais paulistas, para que o livro chegasse aos armários era preciso passar pela autorização do diretor da escola e pelas mãos do bibliotecário, conforme estava previsto na legislação vigente.

O bibliotecário, como responsável pela biblioteca, tinha como incumbência a organização dos livros nos armários e sua disponibilização aos estudantes. Era o bibliotecário que acompanhava as aulas de leitura na biblioteca, orientava os estudantes sobre os materiais existentes ali. Na Escola Normal Primária de Piracicaba, um único bibliotecário atuou no espaço da biblioteca. Em 1911 o secretario-bibliothecario era Fernando Paes de Almeida, cargo que já ocupava na Escola Complementar 6 .

\footnotetext{
${ }^{6}$ A Escola Complementar de Piracicaba foi criada, em 1896, como escola de formação de professores. A primeira turma de alunos formou-se em 1900. Em 1911 ela foi convertida em Escola Normal Primária de Piracicaba, quando todo seu espólio deu origem aos acervos da nova instituição.
} 
A partir da Reforma de 1920, com a unificação das escolas normais pelo modelo da Normal Secundária, o cargo é dividido, ficando como secretário Fernando Paes de Almeida e como bibliotecário João Alves de Souza. Esta lei não previa qual a função do bibliotecário, apenas sugeria que esta era uma prerrogativa do regulamento de cada escola normal de dava, de certa maneira, mais autonomia no gerenciamento deste espaço a cada escola. A formação do bibliotecário, bem como sua função, parece ser elemento essencial na constituição do acervo, uma vez que ele, além da orientação das leituras, também era responsável pela lista de livros a serem adquiridos.

No caso de Fernando Paes de Almeida, por ele ser professor complementarista, ainda que não tivesse conhecimento teórico das questões pedagógicas, pode ter contribuído para a constituição de um acervo voltado para a área da Pedagogia. Por outro lado, como ele acumulava a função de secretário e bibliotecário, a biblioteca permanecia aberta por curtos períodos durante o funcionamento da escola, diferentemente das escolas normais secundárias.

Não há indícios de que os livros, nesse período, fossem catalogados ou tombados, pois não há representação numérica nos carimbos. Somente quando aparecem os carimbos da Escola Normal de Piracicaba, após 1920, é que aparecem os números. Há um selo na lombada de alguns dos livros, com indicação de tombamento, porém, não foi possível identificar sua origem. Como indicado até aqui, são os dispositivos materiais acrescentados pelo bibliotecário que fornecem dados para iniciar a análise, o que o torna agente essencial na mediação entre o autor e o leitor, no caso das bibliotecas escolares.

O bibliotecário era, provavelmente, quem adquiria as obras após a aprovação do diretor da escola. Os livros da biblioteca da Escola Normal Primária de Piracicaba foram publicados entre 1870 e 1918, com substancial concentração nas duas primeiras décadas do século 20. Não há registros, no Livro de Tombo, da forma de aquisição dos livros. Pela análise dos indícios materiais presentes nos livros sabe-se que, no período entre 1911 e 1920, a compra dos livros era feita através da Livraria Augusta, pois há um carimbo desta casa em vários livros.

No entanto, como há uma casa editora em São Paulo com este mesmo nome e há, também, um carimbo diferente dos demais indicando que havia uma Livraria Augusta em Piracicaba, não há como, ao menos até o momento, confirmar a origem dos livros. O livro de Augusto Coelho foi adquirido junto à Livraria Acadêmica, de São Paulo, situada ao lado da Faculdade de Direito de São Paulo. O livro de Leloir, de 1899, foi comprado na Siqueira, Salles \& . $^{7}$, livraria localizada na cidade de São Paulo.

$\mathrm{Na}$ análise material dos livros que compõem o acervo da biblioteca da Escola Normal Primária de Piracicaba é preciso considerar um dado importante, que extrapola a esfera do campo educacional, mas que mantém uma forte intersecção com esse. Trata-se do mercado editorial nos anos iniciais do século 20 .

Segundo Toledo (2007),

a principal característica do mercado editorial, até a década de 1920, era o consumo de livros importados e de livros brasileiros impressos fora do país. Além disso, para se tornar autor era necessário capital para investir e distribuir a própria obra, já que as poucas editoras que existiam publicavam

\footnotetext{
${ }^{7}$ Para maiores detalhes sobre esta livraria ver Razzini (2006).
} 
apenas os livros didáticos, jurídicos e um ou outro escritor de romances de sucesso. Portanto, a idéia de abundância não caracteriza o mercado editorial brasileiro no começo do século 20; pelo contrário, os livros que circulavam eram na sua maioria estrangeiros, trazidos com freqüência por encomenda, sobretudo quando se tratavam de livros de outros gêneros que não a literatura, como os livros científicos ou especializados. (p. 95)

Neste período há poucas casas editoras no Brasil. Algumas tipografias atuavam no setor, como o caso da Typographia do Jornal de Piracicaba ${ }^{8}$ que, no final da década de 1910, publicou uma série de livros, de didáticos a literários, de autores ligados ao grupo dos intelectuais da cidade. A Imprensa Oficial também exercia, como ainda hoje o faz, o papel de publicar livros, folhetos e periódicos, como o caso das publicações da Diretoria Geral da Instrução Pública.

Assim, do conjunto de obras selecionadas e referentes ao momento da Escola Complementar de Piracicaba, com exceção do livro de Cavalcanti (1902), impresso na Tipografia do Diário Oficial do Estado de São Paulo, as demais obras foram todas confeccionadas em editoras estrangeiras, como a Librairie de Firmin-Didot et $\mathrm{C}^{\circ}$, a Hinds Noble \& Eldredge e a Antiga Casa Bertrand-José Bastos \& $C^{\circ}$ Editora que são, respectivamente, francesa, norte-americana e portuguesa. O livro de Hippeau, apesar de não estar mais no acervo, foi considerado como parte dele, uma vez que Rodrigues (1909) oferece elementos para análise material. Este foi impresso na Tipografia Nacional, do Rio de Janeiro, em 1871.

Os livros adquiridos entre 1911 e 1920 começam a esboçar os primeiros passos da constituição de casas editoras nacionais e parcerias entre editoras brasileiras e estrangeiras. Dentre as primeiras, destacam-se a Pocai-Weiss \& $C^{\circ}$., Typographia Siqueira, Nagel \& Comp., a Officinas Graphicas Ezudas, a B. L. Garnier e a Laemmert \& $\mathrm{C}^{\circ}$. As duas primeiras de São Paulo, a Ezudas e a Garnier do Rio de Janeiro e a última com sede em ambas as capitais. Dentre as que possuíam parcerias com casas editoras estrangeiras estão a Francisco Alves, com as empresas Ailland, da França, e Bertrand, de Portugal, ou com a Livraria Ferin, de Lisboa. Dentre as estrangeiras figuram Magalhães \& Moniz, a Livraria Editora de Antonio Figueirinhas, a Livraria Classica Editora e a Guimarães \& C., todas portuguesas. Da França há o livro de Georges Leloir, publicado pela Arthur Rousseau Éditeur.

A entrada de quantidade considerável de livros provenientes de Portugal pode ser explicada, ainda que não exaustivamente, por dois fatores. $O$ primeiro e mais simples deles é a facilidade da leitura representada pela lusofonia. Nas escolas normais secundárias os livros importados eram, na sua maioria, de língua francesa. Esta é uma diferença significativa entre os dois níveis de escola normal que merece ser explorada com mais afinco. Outro fator determinante da entrada de livros portugueses era que, naquele momento, boa parte dos livreiros de São Paulo e do Rio de Janeiro eram portugueses radicados no Brasil.

Numa análise mais ampla sobre os dispositivos textuais e tipográficos presentes nestes livros que compuseram a biblioteca da Escola Normal de Piracicaba há, no período

\footnotetext{
${ }^{8}$ Nessa tipografia era impresso o periódico Jornal de Piracicaba. Nela também foram impressa a revista Educação (1921-1923), periódico da Escola Normal de Piracicaba, e vários livros. Fundada em 1900, ainda hoje publica o Jornal de Piracicaba.
} 
representado pela Escola Complementar, uma prevalência de livros usados pelos professores. O livro de Cavalcanti, engenheiro industrial e civil e lente de Chimica da Escola Polytechnica de São Paulo, conforme indicado na página de rosto, parece ser mais indicado para aulas do curso profissionalizante da área de agricultura, do que para alunos da escola complementar, dada a complexidade de seu conteúdo.

Pode ser que houvesse, no momento em que a Escola Prática de Agricultura começava suas atividades, influência dessa instituição na aquisição de livros para a Escola Complementar, da mesma forma que as aulas de música foram privilegiadas com a construção de uma belíssima sala de música, logo após o hall de entrada. Quando o novo prédio da Escola Normal foi construído, em 1917, os livros de música, todos em capa dura original e de fino acabamento, compunham este acervo como, por exemplo, L'écho des fauvettes e Songs of all the colleges. Honorato Faustino, diretor da escola, era músico e compartilhava com Fabiano e Lázaro Lozano, professores de música, as atividades musicais da escola e da cidade.

Porém, diferentemente do currículo da Escola Complementar, havia obras de Educação e Pedagogia neste acervo. O livro de Hippeau, enquanto um relatório de viagem, expõe o estado da educação na América do Norte. Já o livro de Faria de Vasconcelos é um conjunto de conferências realizadas por ele sobre Pedologia, com indicação de pontos de aplicação nas escolas e outros que necessitavam que as escolas fossem reformuladas. Neste último, uma determinada cultura pedagógica está presente.

João Lourenço Rodrigues, em artigo presente no Anuário de Ensino de 1909, ao revelar aspectos inscritos por Prudente de Moraes no livro de Hippeau, traz indícios para pensar os motivos que levam à doação do livro para a biblioteca da Escola Complementar de Piracicaba. Não foi possível determinar até quando o livro doado por Prudente de Moraes permaneceu no acervo. É possível que ao citá-lo, Rodrigues tenha acendido a curiosidade por parte dos leitores em conhecer melhor o seu conteúdo. Porém, ele traz uma série de elementos de sua materialidade, especialmente em relação às possíveis apropriações feitas por Prudente de Moraes ao deixar suas marcas de leitura:

Essa obra, escripta em francez pelo notável pedagogista Hipeau, foi traduzida e publicada em 1871 por ordem do governo imperial: tem por titulo "A Instrucção nos Estados Unidos". Ao folheal-a, eu senti uma commoção muito real, ao encontrar em algumas das suas paginas certos signaes marginaes, nelle deixados pela mão daquelle que estava predestinado a ser o primeiro governador de S. Paulo, após o advento da Republica. Eis aqui o livro. Ao Lêr os trechos assignalados, eu comprehendi bem os motivos por que o dr. Prudente de Moraes, mal tinha galgado as escadarias do palacio presidencial, decretou a reforma da escola normal e a fundação da escola modelo, medidas essas de vasto alcance para radical regeneração do nosso systema tradicional de ensino. Este livro tinha, pois, a sua historia. Elle levou-me a operar uma como reconstituição do passado e a estabelecer uma approximação. (Rodrigues, 1909, p. 202-203)

Recordando Rousseau e a forma pela qual, em suas meditações, compõe o contrato social, Rodrigues traça um paralelo com as possíveis elucubrações feitas por Moraes quando da leitura do livro de Hippeau: 
O dr. Prudente de Moraes, aqui no silencio da antiga Constituição, foi uma especie de Rousseau; e aquele livro, esquecido agora na estante de uma bibliotheca, foi talvez a fonte maxima onde o seu grande espírito se abeberou daquelle ideal que, havia mais de um século, fizera pulsar na Norte America o grande coração de Washington, o ideal de uma Republica tendo por alicerces a instrucção popular largamente disseminada, consciosamente ministrada. (Rodrigues, 1909, p. 203)

Tais marcas de leitura deixadas por Moraes certamente influenciaram as leituras que outros, porventura, fizeram deste mesmo livro.

Na biblioteca da Escola Normal Primária de Piracicaba houveram livros de educação geral, voltados também aos pais. São representativos desta destinação os livros de Virginia de Castro e Almeida, Como devemos crear e educar nossos filhos; de Agostinho de Campos, Casa de pais, escola de filhos e o Livro de moralidades, de Joaquim Manso. Muitos livros são de apoio às disciplinas da Escola Normal, como os de história geral, Chronica geral do Brazil, de José de Mello Moraes, e Historia da fundação imperio brazileiro, de Pereira da Silva; os das disciplinas de exatas, como Lições de Chimica, de Basin, e Epítome de mechanica, de João Carlos da Silva Borges. Este último traz um dispositivo tipográfico bastante utilizado pelos editores para dar legitimidade ao livro: na folha de rosto vem a informação de que este livro era "Adoptado pela Congregação da Escola Normal Secundária de S. Paulo" e seu autor era professor desta instituição.

Um livro presente no acervo da Escola Normal Primária de Piracicaba merece destaque: O lar domestico. Conselhos para a boa direcção de uma casa ${ }^{9}$, de Vera Cleser. Este livro ensina tudo o que uma boa dona do lar deve saber sobre a organização de uma casa, desde o dia-a-dia até como preparar a mesa de um jantar espacial. Em terceira edição, este livro parece ter sido amplamente divulgado pelo Brasil, pois encontrei referências dele no Estado do Paraná e dois exemplares na Biblioteca Nacional del Maestos, de Buenos Aires.

Outros livros de educação geral, voltados especificamente para a formação de professores, tiveram entrada ao acervo, como os livros No templo de Minerva, O ensino primário no Brazil, de João Pedro Martins, e Educação Republicana, de João de Barros. A propósito da circulação de livros de Agostinho de Campos e João de Barros, pode-se supor que há uma estreita relação com a publicação de um periódico em Portugal e no Brasil: Atlantida, mensário artístico, literário e social para Portugal e Brazil, que foi publicado entre 1915 e 1920 nos dois países, sob a direção de João de Barros e de João do Rio. A presença de Campos e Barros neste periódico parece ter colaborado com a divulgação de seus livros no Brasil.

Para caracterizar a cultura pedagógica que se configura neste acervo serão objetos de análise os livros dedicados à Pedagogia ${ }^{10}$. Para esta análise optei pela classificação feita por Carvalho (2007), em que distingue os tipos de impressos pedagógicos em caixa de utensílios, guia de aconselhamento e tratado de pedagogia. Como são poucos os

\footnotetext{
${ }^{9}$ Este foi um dos títulos adquiridos pela Francisco Alves para ampliação de seu público leitor após 1910 e publicado em 1913, em $3^{\circ}$ edição. Cf. Deaecto, M. M. A livraria Francisco Alves em São Paulo. I Seminário de Livro e da História Editorial, Rio de Janeiro, 2004. Disponível em http://www.livroehistoriaeditorial.pro.br /pdf/marisamidori.pdf. Acesso: 24 jul. 2009.

${ }^{10}$ O livro Educação republicana, de João de Barros, não será analisado devido à precária situação em que o exemplar, localizado na biblioteca da Escola Normal, se encontra.
} 
livros desta categoria, trabalharei com a materialidade de cada um deles para, em seguida, caracterizar a cultura pedagógica através da análise do conjunto de livros.

O modelo representado pela caixa de utensílios se organiza de modo a fornecer ao professor elementos para usar em sala de aula. O método intuitivo é, assim, prescrito no conjunto ordenado pelo impresso, caracterizando a pedagogia prática ou arte de ensinar, em que ensinar a ensinar é fornecer bons modelos:

Nesse modelo, a pedagogia entendida como corpus doutrinário sistematizado, quando requerida, articula-se como conjunto de preceitos que se pretendem indutivamente estabelecidos mediante da experiência e o exemplo de mestres exímios na arte de ensinar. (Carvalho, 2007, p. 24)

O livro de Hippeau ${ }^{11}$, doado por Prudente de Moraes, ao fornecer elementos sobre o funcionamento do modelo escolar norte-americano, traz relevantes informações sobre o método intuitivo. Ao tomar o exemplo dos Estados Unidos como de difusão das luzes e desenvolvimento da educação popular como forma de organização democrática, Hippeau

caracteriza uma operação que constrói um programa a ser seguido pelas nações, no qual a América é apresentada como modelo. Trata-se, portanto, de um conjunto de discursos que, no registro preciso do que vê em cada país, termina por defender a americanização como saída para os problemas da liberdade, gratuidade, obrigatoriedade, secularização e higienização dos estabelecimentos educacionais, em todas as modalidades e níveis de ensino. (Gondra, 2002, p. 162)

Este livro fazia parte do conjunto de livros que compunham a biblioteca da Escola Normal da Capital, no final do período monárquico.

Primeiras lições de coisas. Manual de ensino elementar para uso dos paes e professores, de Norman Allison Calkins, é um manual de ensino norte-americano com edições brasileiras feitas até 1950. A edição presente na biblioteca da Escola Normal Primária de Piracicaba ${ }^{12}$ é justamente a primeira publicada no Brasil, pela Imprensa Nacional, em 1886. A tradução de Ruy Barbosa foi feita a partir da $40^{a}$ edição.

O livro é aberto por uma declaração do ex-inspetor da instrução pública da Corte A. H. de Souza Bandeira Filho, em que ele aponta a importância da aplicação, pelos professores das escolas primárias, dos métodos intuitivos, ainda pouco utilizados. Dentre as dificuldades que, segundo ele, os professores encontravam estava a ausência de livros de metodologia, nos quais "os professores colhessem noções acertadas sobre o uso dos processos intuitivos" (Calkins, 1886, p. 3). Este dispositivo, ao lado do fato de que Ruy Barbosa era naquele momento conselheiro de Estado, atestava a autoridade conferida ao livro, ainda mais que o inspetor afirmava que os métodos intuitivos eram aplicados nas escolas de todos os povos cultos.

Norman Allison Calkins, norte-americano nascido em 1822, dedicou-se desde jovem ao ensino, como professor e como diretor de escola. Em Nova York, em 1846, começou a

\footnotetext{
${ }^{11}$ Por não ter um exemplar do livro para analisar me apoiei em Carvalho (2007) e Gondra (2002) para esta análise.

12 Há dois exemplares deste livro, ambos adquiridos pela Escola Normal Primária. O livro tem marcas de manuseio tendo sido, inclusive, recortado.
} 
tratar da renovação dos métodos de ensino, fortemente influenciado por Pestalozzi. Ocupou vários postos dentro da National Education Association e chegou a ser presidente. Primeiras lições de coisas é resultado das preocupações de Calkins com as dificuldades encontradas pelos professores "em adaptar, por si próprios, as idéia de Pestalozzi à prática corrente do ensino" (Lourenço Filho, 2001, p. 79). Calkins elaborou um formulário de lições que, refundido a ampliado, se transformou no livro Primary object lessons, publicado em 1870.

Segundo Valdemarin (1998), ${ }^{13}$

as Primeiras lições de coisas de N. A. Calkins abrangem a maior parte do conteúdo a ser ministrado no ensino elementar, acompanhadas dos passos metodológicos a serem observados pelo professor na atividade de ensino. Este conteúdo, no entanto, não é apresentado na seqüência em que deve ser ensinado. Em coerência com os princípios norteadores do método, as lições são organizadas segundo o critério da importância atribuída a cada um dos sentidos para a aquisição do conhecimento, iniciando-se pelos conteúdos mais adequados à percepção visual e finalizando com aqueles que têm no tato seu suporte cognitivo. (p. 77)

Este livro, por abordar um conjunto de lições a serem seguidas pelos professores e pais, se constitui numa caixa de utensílios e fornece as condições necessárias ao exercício de ensinar pensado enquanto arte. Nota-se que essa categoria de impressos chega à Escola Normal Primária de Piracicaba por meio de autores norte-americanos.

No conjunto de livros que podem ser caracterizados como guia de aconselhamento encaixa-se, principalmente, aqueles de educação geral voltados para professores. Os impressos do tipo guia de aconselhamento são caracterizados por serem carregados de "preceitos moralizantes que visam moldar, segundo representações éticas de longa tradição no pensamento teológico-político europeu, um novo tipo profissional: o professor" (Carvalho, 2007, p. 25). Para operacionalizar tais idéias, os impressos desta categoria, forneciam ao professor "informações e conselhos úteis para o exercício da arte de ensinar" (Carvalho, 2007, p. 25). Nesta categoria se encaixam os livros do português Agostinho de Campos.

Nascido em Porto, em 1870, Agostinho de Campos apresenta traços políticos e pedagógicos confusos e conflitantes. Formou-se em Direito e exerceu a profissão de jornalista e professor. Foi diretor-geral da Instrução Pública nos últimos governos da Monarquia, teve sua produção intelectual alavancada a partir de 1911, ano em que publica Educação e ensino e a primeira edição de Casa de pais, escola de filhos. No prefácio a segunda edição, Campos (1917) adverte:

Se esta obra fôsse um poema ou um romance, uma obra de arte pela arte, poderia o autor entregar-se ás delícias do êxito; mas a verdade é que êle, imodesta e pretenciosamente, procurou organizar um guia, um guia de procedimento - e de mais a mais em assunto de tão alto vulto, como é a educação das crianças. (p. Vl)

\footnotetext{
${ }^{13}$ Para esta autora, o manual de Calkins teve sua "primeira edição em 1861, nos EUA, sendo refundida e ampliada em 1870, largamente utilizado nos EUA e definido como a melhor obra para o ensino já publicada, fato que motivou várias traduções, inclusive a brasileira, que vem a público em 1886" (Valdemarin, 1998, p. 96).
} 
Em Educação e ensino, Agostinho de Campos busca traçar considerações de ordem geral sobre analfabetismo, passando pela direção da escola, os prédios e materiais escolares, terminando com os mandamentos do bom professor, que é a parte que mais caracteriza este livro como guia.

O modelo Tratado de pedagogia se organiza de forma diferenciada da caixa de utensílios e do guia de aconselhamento. No Tratado, a Pedagogia passa a fornecer fundamentos sobre o ensinar e não mais modelos. Os métodos são dissociados da prática. Assim,

amalgamando princípios ditos filosóficos ou científicos com saberes extraídos da experiência de casos considerados de bom senso e muita vez de senso comum acumulados como cultura escolar informal, o Tratado de pedagogia se configura como manual que compendia e sistematiza os saberes que estatui necessários ao exercício da docência. (Carvalho, 2007, p. 30)

A principal característica deste modelo era oferecer a dimensão científica da atividade pedagógica. Nesta categoria, dois títulos foram encontrados na biblioteca da Escola Normal Primária de Piracicaba.

Lições de pedologia e de pedagogia, de Faria de Vasconcelos, é o livro mais antigo desta categoria encontrado no acervo desta biblioteca, tendo sido adquirido enquanto ainda era Escola Complementar. Com data provável de publicação entre 1909 e 1910, ele chegou à biblioteca da Escola Complementar antes de 1911, ou seja, com pouquíssimo intervalo entre a publicação e a aquisição pela biblioteca. Fruto de um conjunto de conferências proferidas por Vasconcelos para Liga de Educação Nacional, uma das muitas associações educativas portuguesas da época, este livro traz "uma síntese de divulgação do labor que como estudante, professor e investigador levava de sete anos na Bélgica, iniciado nas Ciências Sociais e depois melhor definido na área da Psicologia e da Psicologia como suporte da Pedagogia" (Nóvoa, 2003, p. 32).

$\mathrm{Na}$ introdução, Faria de Vasconcelos informa que o livro contém uma

systhematisação e vulgarização que a muitos, apesar das suas imperfeições, póde ser útil. Numerosas indicações que n'ellas se contêm são de applicação immediata e indispensavel nas escolas actuaes. Outras suppõem uma organização escolar inteiramente differente da existente. Mas tanto umas como outras obedecem a este princípio fundamental em Pedagogia: adaptação do ensino e da educação ao desenvolvimento natural, physico e psychico, da creança. (Vasconcelos, F., s/d, p. 7)

O livro teve três edições, com um total de 586 páginas, impresso na Antiga Casa Bertrand, em Lisboa. Sua organização, em doze lições, tem por base a necessidade de estudar e compreender a criança como tal. Daí se basear no que o autor chama de sciencia educativa. Vasconcelos, até então, havia se formado em Direito na Universidade de Coimbra. Mudou-se, em seguida, para a Bélgica para estudar na Universidade Nova de Bruxelas, onde foi professor catedrático de Psicologia e Pedagogia, tendo como colega Adolphe Ferrière, um dos expoentes da Educação Nova na Europa. 
Outro autor português que também foi autor de manuais do tipo tratado foi José Augusto Coelho. Ao invés do seu já conhecido Princípio de pedagogia, o livro que aparece na biblioteca da Escola Normal Primária de Piracicaba é Manual pratico de pedagogia para uso dos professores em geral e em especial dos professores do ensino medio e primario. Na escola normal da capital, Princípio de pedagogia compunha a bibliografia da cadeira de Pedagogia e Direção de Escolas, em 1893 (Prestes, apud Carvalho, 2006, p. 154). Boto, analisando as principais produções de Coelho, afirma que ela está toda alicerçada nos moldes do tratado. O Manual pratico de pedagogia de Coelho

constitui declaradamente um material didático para a formação de professores. Trata-se de um livro de Pedagogia, que apresenta seu campo de alcance à luz do que nomeia ciência da educação. O texto é composto por várias partes que integram o que é apresentado como conhecimento científico da matéria da educação. Parte-se da premissa segundo a qual não seria possível proceder ao ato educativo caso não se conheça quer do ser que se ensina e educa, quer dos princípios mais essenciais da Ciência teórica em que se funda. Sem um sólido saber pedagógico, criteriosamente palmilhado, o professor avançará constantemente às cegas. (Boto, 2007, p. 8)

Augusto Coelho era fortemente influenciado pelos princípios positivistas. Foi professor da Escola Normal do Porto e responsável pela cadeira de Pedagogia e colaborou com a imprensa normalista desta escola. Em 1894 transferiu-se para a capital e ingressou na Escola Normal de Lisboa, onde assumiu o cargo de diretor da Escola Normal Primária para o sexo masculino. Colaborou ativamente com a imprensa de educação e ensino, fortemente alicerçada na capital portuguesa.

A circulação das idéias de Augusto Coelho no Brasil foi, segundo Carvalho, estimulada pelos positivistas republicanos, o que "certamente alimentou redes de relações internacionais em que promoveu o contato entre intelectuais e políticos" (Carvalho, 2006, p. 155).

É possível indicar que este momento é marcadamente de profusão de princípios pedagógicos de diferentes matizes. Tanto a Escola Complementar, quanto a Escola Normal Primária de Piracicaba sofreram influência norte-americana devido à presença dos metodistas na cidade, que fundaram o Colégio Piracicabano.

No entanto, a entrada do livro de Calkins na Escola Normal Primária de Piracicaba parece destoar um pouco dos caminhos pelos quais a Pedagogia se direciona, sobretudo, com a indicação de instalação do Gabinete de Psicologia e Pedagogia, após 1910. Por outro lado, se perfila com o conjunto de livros trazidos por Thompson dos Estados Unidos, em especial, o livro de Emerson White, $A$ arte de ensinar.

Algo, no entanto, parece fora de lugar. É a presença de livros caracterizados como tratado de pedagogia. Fora de lugar por dois motivos. O primeiro porque são provenientes da Europa, notadamente, de Portugal, e não dos Estados Unidos. Em segundo lugar, porque este impresso se empenha em caracterizar a cientificidade da Pedagogia, calcada em áreas afins, como a Psicologia, a Biologia e a Sociologia e acompanha o florescimento da Pedagogia como disciplina. O livro de Faria Vasconcelos, Lições de pedologia e de pedagogia, é incorporado ao acervo da Escola Complementar, onde não havia uma disciplina de formação pedagógica na estrutura curricular. 
Indícios sobre práticas de leituras instituídas na Escola Normal Primária de Piracicaba começam a aparecer somente após 1920. A imagem da aula de leitura na biblioteca, de 1922, presente no acervo iconográfico da escola, mostra como ela se organizava. Honorato Faustino, em artigo da Revista de Educação sobre os métodos ativos nas Escolas Normais e Complementares, afirma que os professores devem indicar, aos seus alunos, leituras para que estes freqüentem as bibliotecas escolares, que deveriam ser fomentadas pelo Estado, com "obras de real valor" (Faustino, 1921, p. 71).

\section{Referências}

BOTO, Carlota. A arte de tornar ciência o ofício de ensinar: compêndios pedagógicos de Augusto Coelho. REUNIÃO ANUAL DA ANPED, 30, 2007, Caxambu. Anais ... Caxambu: Anped, 2007.

CALKINS, Norman Alisson. Primeiras lições de coisas: manual de ensino elementar para uso de paes e professores. Rio de Janeiro: Imprensa Nacional, 1886.

CAMPOS, Agostinho de. Casa de pais, escola de filhos. Rio de Janeiro: Livraria Francisco Alves, 1917.

CARVALHO, Marta Maria Chagas de. A caixa de utensílios e a biblioteca: pedagogia e práticas de leitura. In: VIDAL, Diana Gonçalves; HILSDORF, Maria Lúcia Spedo. Tópicas em história da educação. São Paulo: Edusp, 2001, p. 137-168.

CARVALHO, Marta Maria Chagas de; FREITAS, Marcos Cesar; MOGARRO, Maria João; PINTASSILGO, Joaquim (org.). História da Escola em Portugal e no Brasil: circulação e apropriação de modelos culturais. Lisboa: Colibri/Centro de Investigação em Educação da Faculdade de Ciências da Universidade de Lisboa, 2006.

CARVALHO, Marta Maria Chagas de e TOLEDO, Maria Rita de Almeida. Os sentidos da forma: análise material das coleções de Lourenço Filho e Fernando de Azevedo. In: OLIVEIRA, Marcus A. T. Cinco estudos em história e historiografia da educação. Belo Horizonte: Autêntica, 2007, p. 89-110.

CAVALCANTI, Adolfo. Curso de zootechnia geral e especial. São Paulo: Typographia do Diário Oficial de São Paulo, 1902.

CHARTIER, Roger. A ordem dos livros: leitores, autores e bibliotecas na Europa entre os séculos 14 e 18. Brasília: UnB, 1994.

DEAECTO, Marisa Midori. A livraria Francisco Alves em São Paulo. SEMINÁRIO DE LIVRO E DA HISTÓRIA EDITORIAL, 1, 2004, Rio de Janeiro. Anais ... Rio de Janeiro: Casa de Rui Barbosa/UFF, 2004. Disponível em: <http://www.livroehistoriaeditorial. pro.br/pdf/marisamidori.pdf>. Acesso em: 24 jul. 2009.

ELIAS NETTO, Cecílio. Memorial de Piracicaba. Século 20. Piracicaba: Instituto Histórico e Geográfico de Piracicaba/Jornal de Piracicaba/Unimep, 2000.

FAUSTINO, Honorato. O ensino activo nas escolas normaes e complementares. Revista de Educação, v. 1, n. 2, 1921, p. 71. 
GONDRA, José Gonçalves. Olhos na América: uma leitura dos relatórios de C. Hippeau. Educar. Curitiba: UFPR, n. 19, 2002, p. 161-185.

HILSDORF, Maria Lúcia Spedo. Lourenço Filho em Piracicaba. In: SOUSA, Cynthia Pereira de (org.). História da educação: processos, práticas e saberes. São Paulo: Escrituras, 1998, p. 95-112.

JACOB, Christian; BARATIN, Marc (orgs.). O poder das bibliotecas: a memória dos livros no ocidente. Rio de Janeiro: UFRJ, 2000.

LOURENÇO Filho, Rui (org.). Lourenço Filho, Manoel Bergstrom: a formação de professores - da escola normal à escola de educação. Brasília: Inep, 2001.

NERY, Ana Clara Bortoleto. Divulgando práticas e saberes: a produção de impressos pelos docentes das Escolas Normais do Brasil (1911-1950). Marília: M3T, 2007.

NERY, Ana Clara Bortoleto; SILVA, Emerson Correia da. O periódico Excelsior! (19111916) como ponto de observação do campo de formação de professores. Série Estudos, Campo Grande: UCDB, v. 26, 2008, p. 175-186.

NÓVOA, António (coord.) Dicionário de educadores portugueses. Porto: ASA, 2003.

RAZZINI, Marcia de Paula Gregório. A produção didática da Tipografia Siqueira: caminhos de pesquisa. CONGRESSO BRASILEIRO DE CIÊNCIAS DA COMUNICAÇÃO, 19, 2006, Brasília. Anais ... São Paulo: Intercom, 2006.

RODRIGUES, João Lourenço. Annuario do Ensino. São Paulo: Diretoria Geral da Instrução Pública, 1909.

SOUZA, Luciene Soares de. Bibliotecas e grupos escolares: práticas educativas na cultura escolar de São Paulo (1890-1920). CONGRESSO BRASILEIRO DE EDUCAÇÃO, 5, 2008, Aracaju. Anais ... Aracaju: SBHE, 2008.

TANURI, Leonor Maria. O ensino normal do estado de São Paulo 1890-1930. São Paulo: USP, 1979.

TOLEDO, Maria Rita de Almeida. Coleção atualidades pedagógicas: do projeto político ao projeto editorial (1931-1981). São Paulo: PUCSP, 2001. 295f. Tese (doutorado em Educação). Programa de Pós-Graduação em Educação, Pontifícia Universidade Católica de São Paulo.

VALDEMARIN, Vera Teresa. O conhecimento do mundo: um estudo sobre concepções epistemológicas e sua aplicação escolar. Perspectiva. Florianópolis: UFSC, v. 16, n. 29, 1998, p. 75-109.

VASCONCELOS, Faria de. Lições de pedologia e de pedagogia. Lisboa: Antiga Casa Bertrand, s/d.

VIDAL, Diana Gonçalves. Bibliotecas escolares: experiências escolanovistas nos anos de 1920-1930. In: MENESES, Maria Cristina. Educação, memória, história. Campinas: Mercados das Letras, 2004, p. 187-212. 
ANA CLARA BORTOLETO NERY é professora adjunta da Faculdade de Filosofia e Ciências da Unesp, campus de Marília. Doutora em Educação pela Faculdade de Educação da Universidade de São Paulo, com graduação em Pedagogia e mestrado em Educação pela Universidade Federal de São Carlos. Docente e coordenadora do Programa de Pós-Graduação em Educação.

Endereço: Rua Murutinga do Sul, 98 - 07021-060 - Guarulhos - SP - Brasil.

E-mail: neryanaclara@gmail.com.

Recebido em 19 de junho de 2012.

Aceito em 8 de dezembro de 2012. 